\title{
Cavaleiros, amantes e mambembes
}

\author{
FÁTIMA SAADI
}

La pièce Götz von Berlichingen, le roman épistolaire Les souffrances du jeune Werther et le Bildungsroman La mission théâtrale de Wilhelm Meister, écrits par le jeune Goethe pendant sa période d'affinité avec le mouvement Sturm und Drang, sont discutés dans cet article comme des instruments de lutte de la culture germanique contre l'hégémonie de la culture française, qui se perpétue depuis le classicisme du XVIIe siècle comme le seul modèle admis en matière artistique en Allemagne. Harmonie, symétrie, concision, abstraction, unité d'action laissent la place, dans les oeuvres citées, au difforme, au grotesque, à l'exagération, à l'observation du réel, à la prolifération des incidents et à la supériorité du personnage par rapport à la trame des faits. L'affinité des textes analysés avec l'oeuvre dramatique du jeune Lenz est signalée. Dans la pièce Götz, sont soulignés les aspects structuraux qui la rendent emblématique de la rupture avec la poétique dramatique française. Dans Les souffrances..., ressortissent de l'analyse le sentimentalisme et l'individualisme, tandis que dans le Bildungsroman, c'est le modèle shakespearien qui est discuté, considéré par les Stürmer comme plus proche des traditions allemandes que la poétique française.

GOETHE / STURM UND DRANG / GÖTZ VON BERLICHINGEN / ESTHÉTIQUE THÉÂTRALE / HISTOIRE DU THÉÂTRE

Em 1770, o jovem Goethe (1749-1832) está em Estrasburgo, cidade limite entre o domínio germânico e a França, estudando direito, ciências políticas e história, e assistindo a aulas de anatomia, cirurgia e química, expediente por meio do qual tentava satisfazer à sua infinita curiosidade a respeito das ciências humanas, sociais e naturais, e também ao desejo de seu pai de vê-lo transformado em advogado.

No último terço do século XVıII, a Alemanha vivia uma situação de transição. Dividida em inumeráveis unidades políticas, a maioria governada de forma absoluta por aristocratas sem o menor interesse pela coisa pública, esse conglomerado de principados, ducados, condados e algumas cidades livres assiste à ascensão militar da Prússia, administrada com mão de ferro por Frederico II. No âmbito social, a burguesia ainda não faz ouvir a sua voz no domínio público, mas em 
breve seus valores, em particular o individualismo, vão marcar a arte de modo definitivo.

A vitória militar de Frederico II sobre a França na Guerra dos Sete Anos (1756-1763) não altera em nada o desdém do imperador em relação à arte alemã, como demonstra Norbert Elias em $O$ Processo Civilizador (1980). Educado na tradição francesa, Frederico II partilha da tese, muito difundida naquela época, de que a inclinação dos Alemães pela mistura entre extremos, como o sério e o cômico, o baixo e o sublime, redunda em irremediável mau gosto e que a cultura francesa, em sua busca pela «harmonia do todo e pela pureza da forma» (Goethe, 1987: 21) seria a detentora do modo mais eficaz e, por isso canónico, de se obter o belo.

Em 1770, fazia pouco mais de cem anos que Estrasburgo tinha sido anexada à França por Luís XIV, mas a cidade ostentava as marcas evidentes de seu passado germânico, a maior delas a catedral, que encantou o jovem Goethe desde sua chegada à cidade. Mal deixou suas coisas na estalagem Espírito, correu até à catedral e subiu ao alto da torre (Goethe, 1971: 277).

Daquele posto privilegiado de observação entre dois países e duas culturas, era possível pôr em perspectiva a mediocridade da vida pública alemã; as dificuldades dos artistas num país em que a classe média ainda não havia se constituído como mercado consumidor de obras criadas à sua imagem, desejando se igualar à aristocracia pelo consumo dos bens culturais que distinguiam a nobreza.

Educado, como os jovens bem-nascidos de sua época, segundo o modelo francês de bom gosto, que preconizava a harmonia do todo e a pureza da forma, a primeira sensação de Goethe diante da Catedral de Estrasburgo foi muito confusa. Por um lado, ele estava habituado a ver reunido sob o termo gótico tudo o que era «indefinido, imoderado, artificial, improvisado, enfeitado ou supérfluo» (Goethe, 1987: 22), mas, por outro lado, a apreciação detalhada da catedral lhe abriu os olhos para outro tipo de unidade, a unidade de milhares de detalhes que produziam uma expressão de grandiosidade que se identificava com o espírito germânico.

Nova postura diante da arte e da vida: valorização da natureza e do gênio criador, recuperação da tradição nacional e de objetos artísticos até então desdenhados. Esse foi o ideário do movimento que, a posteriori, ficou conhecido como Sturm und Drang, Tempestade e Ímpeto, e que trouxe ao centro da cena o sentimento, as emoções, a óptica individual na análise da vida, a independência em relação às regras poéticas, 
à etiqueta aristocrática, à rígida separação entre os estamentos sociais. O jovem Goethe ficou conhecido como o mais destacado dos Stürmer, especialmente graças a suas primeiras obras: a peça Götz von Berlichingen (1772) e o romance epistolar Os Sofrimentos do Jovem Werther (1774). No entanto, o movimento, cujo auge se deu entre 1770 e 1780 , contou com vários outros integrantes, entre os quais se destacou o igualmente jovem Jakob Michael Reinhold Lenz (1751-1792). A amizade entre os dois escritores era tão próxima que alguns chegaram a acreditar que Goethe fosse o autor do manifesto teatral do Sturm und Drang, Notas sobre o Teatro, escrito por Lenz em 1771 e publicado em 1774, e também da peça O Preceptor (primeiro esboço em 1772).

As Notas sobre o Teatro são a introdução à tradução/adaptação que Lenz fez da peça de Shakespeare Trabalhos de Amor Perdidos, cujo título ele alterou para Amor vincit omnia (O Amor tudo Vence). O manifesto reflete o interesse de Lenz por Shakespeare e pela novíssima literatura de seu tempo, sendo tributário também dos cursos de Kant, a que assistira na Universidade de Königsberg. Como Lessing, Lenz também utiliza Shakespeare como modelo dramatúrgico e, em consequência, como argumento desqualificador da tragédia clássica francesa.

Para Lenz, os caracteres são mais importantes que a trama dos fatos. A contraposição a Aristóteles é flagrante, mas o jovem Stürmer procura compreender o filósofo pondo-o em perspectiva histórica: o filósofo raciocinava em consonância com o seu tempo, e, por isso, atribuía aos deuses e ao destino as causas primordiais das ações dos homens (Aristóteles, 1994: 448; Lenz, 2006: 36). Mas o espectador do fim do século XVIII não pode se contentar com isso:

Nós odiamos ações cuja razão não compreendemos, e delas não participamos. É por isso que os aristotélicos de hoje, que se contentam em pintar as paixões sem os caracteres (cujo valor, no entanto, eu reconheço, apesar de deles divergir), se veem constrangidos a empregar uma única psicologia para todos os personagens, a partir da qual podem deduzir de forma hábil e com total liberdade os fenômenos de suas ações e que, no fundo - com a devida vênia desses senhores - nada mais é do que a psicologia deles. Onde fica então o poeta, leitor cristão? Onde fica o espelho? Esses senhores podem até ser grandes filósofos, ter grande conhecimento do homem em geral e das leis da alma humana, mas onde fica o conhecimento do individual? Onde o conhecimento que não se afasta enojado, que conserva sempre o mesmo brilho e a mesma capacidade de mostrar a 
imagem, quer ela tenha sido buscada no peito do coveiro ou sob a crinolina da rainha? (Lenz, 2006: 36-37)

É importante ressaltar também que a crise que se instala entre a poética normativa de viés francês/aristotélico e a estética teatral que começa a se esboçar por obra dos artistas da segunda metade do século XVIII é tributária de um novo paradigma que tem as ciências naturais como referencial e que vem substituir o paradigma vigente ao longo do século XVII e até, digamos, o primeiro terço do século XVIII e que tinha as ciências exatas, especialmente a matemática, como modelo.

Em que afeta isto a arte? Na mudança de método: o método dedutivo, que parte de um modelo (no caso da arte, a ideia de bela natureza) para criar as obras individuais, é substituído gradualmente pelo modelo indutivo, no qual a obra é construída a partir da observação dos seres individuais. E, dada a importância atribuída à observação por esse paradigma, novos campos temáticos passam a ser abordados pelas artes: além dos tradicionais assuntos religiosos ou mitológicos, juntam-se outros de interesse específico para a burguesia em ascensão (o trabalho, as falências, as relações familiares, etc.).

Também a postura do espectador muda e ele passa a desejar obras que ele possa decodificar por identificação direta, o que é muito diferente da complexa operação que Aristóteles pressupunha para a catarse e que consistia em uma identificação com um «esquema» de ação (uma abstração) que, por meio da intelecção sensível (o horror e a compaixão causados pelos fatos terríveis que eram apresentados), levava a uma ampliação do conhecimento. A nova postura diante do teatro é ambígua porque solicita uma ampliação do espectro da realidade que se considera digna de figurar em cena (o que alarga o campo temático), mas, na verdade, conduz a uma redução do campo propriamente estético, porque prega a decodificação por semelhança entre o que é mostrado e a realidade. A tarefa passa a ser prioritariamente de reconhecimento, reafirmando o que o espectador já sabe e, na maioria dos casos, sublinhando basicamente as emoções que o novo arranjo ficcional dos dados suscita.

Vejamos o que estas ideias têm de singular. Em primeiro lugar, a noção de que o indivíduo é o centro de interesse da obra, tanto no palco quanto na plateia. Vale lembrar que o termo theatron, que na antiga Grécia se referia ao público e significava «lugar aonde se vai para ver», passa, a partir do Renascimento, a designar também o palco, sendo que no século XviıI a palavra já se refere ao edifício 
teatral como um todo. Como, naquela época, o espetáculo teatral era a mais pública das diversões, o teatro passa a ser o lugar aonde se vai para ser visto (e não me deixam mentir os camarotes de proscênio e, sobretudo, as banquetas de palco, nas quais se instalavam os espectadores que se dispunham a pagar pelo privilégio. As banquetas só foram eliminadas em 1759 na Comédie-Française e persistiram ainda por bastante tempo em outros teatros).

Em segundo lugar, no caso específico da Alemanha, a partir de 1750, registra-se o interesse por temas relativos à história, à sensibilidade e aos ambientes alemães.

Em terceiro lugar, afirma-se a revalorização de Shakespeare, que apresenta um modo mais épico de codificação do mundo do que o modelo dramatúrgico francês. Shakespeare trabalha com a amplitude temporal das tramas e é sempre muito atento ao ambiente social em que elas se desenrolam, enquanto o modelo francês trabalha por concentração da ação e abstração das personagens.

Em quarto lugar, o indivíduo passa a ser não apenas o centro de interesse temático da cena, trazendo a primeiro plano sua psicologia e suas emoções, mas se reafirma de modo decidido na noção de gênio: aquele que cria sem as limitações impostas pelas poéticas normativas porque está em contato direto com as forças da natureza, que consegue expressar de forma absolutamente livre em suas obras.

Esses elementos - individualismo, gênio, natureza, interesse pelo passado nacional - podem nos ajudar a compreender a obra dramatúrgica do jovem Goethe, em especial o drama histórico Götz von Berlichingen (escrito em 1772 e depois remanejado em 1773), que, segundo o próprio Goethe, foi criado em seis semanas, sem plano prévio e praticamente sem rasuras (Goethe, 1988b: 559-60; Carlson, 1978: 14), por um autor «totalmente identificado com seu tema, que foi avante sem se desviar, sem olhar para trás, nem à direita nem à esquerda» (Goethe, 1971: 439), num processo de criação típico dos gênios.

Foi em Estrasburgo, provavelmente em 1771, que Goethe tomou conhecimento da existência do cavaleiro medieval Götz von Berlichingen, que nasceu em 1480 na Francônia e morreu em 1562, tendo sido, portanto, contemporâneo de Lutero (1483-1546). O próprio cavaleiro, que havia perdido uma das mãos em combate, ditou ao seu capelão as memórias intituladas Geschichte Gottfriedens von Berlichingen, mit der eisernen 
Hand (História de Götz de Berlichingen, com a mão de ferro), que Goethe seguiu bastante de perto para a criação de sua peça. ${ }^{1}$

Provavelmente o que o atraiu na história do cavaleiro foi, mais que tudo, sua liberdade de senhor feudal. Só o prendia o juramento prestado ao imperador, que estava longe o suficiente para que Götz se sentisse totalmente autônomo em seus domínios e em suas ações. Livres assim deveriam também ser os poetas alemães que precisavam sacudir o jugo dos Franceses, recorrendo a Shakespeare como modelo. E Götz servia à maravilha como tema de uma peça em que o interesse não estaria na unidade de ação, no encadeamento necessário dos fatos, mas nas múltiplas aventuras do protagonista. Além disso, o panorama cultural alemão no medievo parecia a Goethe rico e original. Daí sua admiração por Erwin, o arquiteto que, no século XIV, trabalhou na construção da Catedral de Estrasburgo, considerada por Goethe um eloquente testemunho da originalidade do espírito alemão «enquanto os italianos não podem se jactar de qualquer estilo distintamente nacional e, muito menos, os franceses» (Goethe, 1987: 23).

Seguindo o que Goethe imaginava ser o modelo shakespeariano, Götz inaugura um gênero, o drama de cavalaria, que conheceu enorme sucesso na Alemanha. O texto foi publicado em 1773, em edição do autor: Goethe pagou o papel e seu amigo Merck a impressão. Ambos empacotaram os exemplares do texto e os enviaram aos principais livreiros alemães. Logo, no entanto, surgiu uma edição pirata, e Goethe e Merck tiveram de arcar com o prejuízo total do empreendimento (Goethe, 1971: 440-1).

A peça, considerada «impertinente» (Grappin, 1988: 1537) pela crítica conservadora, foi recebida pelos jovens com grande entusiasmo. Goethe tinha então 24 anos. Em seguida, escreveria Werther, tornando-se famoso não só na Alemanha, mas na Europa inteira.

Götz apresenta a si mesmo em suas memórias como um «cavaleiro sem medo e sem mácula, em meio a inimigos astutos e traiçoeiros» (idem: 1538), no entanto, a verdade histórica é que, além das guerras feudais em que esteve envolvido, Götz promoveu uma série de incursões que poderiam ser qualificadas simplesmente de pilhagens. $O$ imperador Maximiliano I havia proibido as guerras privadas no intuito de centralizar a autoridade e o exercício da força nos domínios germânicos, mas a situação turbulenta, com a eclosão da Reforma, das guerras religiosas

1 Muitas das informações a respeito da gênese da peça se baseiam na «Introdução» feita por Pierre Grappin para a tradução francesa de Götz von Berlichingen publicada pela Pléiade (Grappin, 1988: 1533-45) e em Brufford (1975). 
e das revoltas camponesas que se seguiram, tornou impossível a pretendida centralização do poder.

Goethe pautou sua peça pela visão heroica que o cavaleiro tinha de si mesmo, contrapondo-o à mesquinharia e ao artificialismo de seus inimigos, ocupados com intrigas de corte e ardis desleais. $\mathrm{O}$ pessimismo de Goethe quanto à situação de seu país foi reforçado por seu estágio, em 1772, como advogado no Tribunal Imperial em Wetzlar, onde se acumulavam, naquele momento, vinte mil processos, cujo tempo de tramitação era, em média, de dez anos. $\mathrm{O}$ tribunal havia sido fundado pelo imperador Maximiliano e jamais havia funcionado de forma satisfatória (idem: 1536). Ao voltar dessa viagem, e espicaçado pela crítica de Herder, que lhe disse simplesmente que Shakespeare o tinha «desencaminhado», Goethe rescreve seu texto, dando ainda mais ênfase à figura do protagonista, que reúne as virtudes individuais do perfeito cavaleiro - coragem, lealdade, sinceridade, honestidade, generosidade -, mas não está absolutamente aparelhado para lidar com os meandros da política absolutista que está se instalando e, no seu entender, substituindo o valor pessoal pela retórica e pela astúcia. A morte do imperador e a de Götz no quinto ato simbolizam exatamente o fim de uma era. E o horror dos tempos que se iniciarão é prenunciado, desde o começo desse ato, por uma série de fenômenos naturais, como a passagem apavorante de um cometa, chuvas torrenciais e incêndios que desenham estranhas figuras no céu. Evidentemente o público contemporâneo de Goethe estabelecia uma clara analogia entre a fraqueza do imperador medieval e o estilhaçamento do domínio germânico, enredado em conflitos administrativos e de classes, entregue à mania de admirar os franceses, acima de tudo, e sofrendo com a venalidade das cortes (Brufford, 1975: 206).

O desejo do jovem Goethe por um futuro baseado nas virtudes individuais se junta a seu interesse pelos movimentos de revalorização do sentimento, na esteira do pensamento de Rousseau, e, sobretudo, revela a falta de horizonte político dos Alemães naquele momento. Não deixa de ser reacionária, do ponto de vista político, essa exaltação do feudalismo e do sistema patriarcal, mas, num país ainda tão dependente desse sistema como a Alemanha do século XVıII, é compreensível que se queira, ao menos, que os homens que têm influência sobre a vida pública tenham fibra e caráter. A alternativa apresentada por Goethe opõe o valor individual sem capacidade de articulação política à astúcia política sem preocupação alguma com o bem comum. 
Götz, senhor do Castelo de Jagsthausen, nos é mostrado em diferentes circunstâncias de sua vida ao longo de dez anos. A peça, dividida em cinco atos e quase sessenta cenas, acompanha as escaramuças entre Götz e o bispo de Bamberg; o assalto que Götz leva a cabo contra os comerciantes de Nuremberga, que voltam para casa depois de uma feira; a prisão de Götz em Heilbronn e sua libertação por um aliado; a liderança da revolta camponesa que Götz é forçado a assumir e que sela seu destino.

Goethe acreditava que um autor de teatro deve ter o que dizer, claro, mas o mais importante é dizê-lo em termos acessíveis e de modo vivo, por meio de quadros, de imagens (Grappin, 1988: XXXVIII). E sua técnica dramatúrgica procura sempre criar uma ambiência pulsante, na qual circulam personagens que ajudam a explicitar o conflito (a presença maciça de camponeses como móvel da ação é mais uma das novidades que a peça apresenta).

A peça se abre com uma conversa, na taverna, a respeito da querela entre Götz e o bispo de Bamberg. Alguns camponeses descrevem, em linhas gerais, a situação: louvam Götz, que, podendo tirar vantagem em relação ao bispo, foi generoso, selando um acordo de paz com ele. Pouco depois, no entanto, o bispo sequestrou um dos vassalos de Götz, que, por sua vez, armou uma emboscada para apanhar o bispo. Mas alguém traiu o plano e o golpe falhou. Os camponeses partidários de Götz acabam por provocar a ira de dois homens de armas do bispo, que também estão bebendo no albergue. Chegam às vias de fato. $\mathrm{O}$ taberneiro os separa, e os homens do bispo saem no momento mesmo em que dois cavaleiros de Berlichingen chegam. A partir da informação fornecida pelos camponeses de que Weislingen, braço-direito do bispo, está no castelo senhorial da região, os dois cavaleiros poderão armar com Götz uma estratégia para forçar a libertação do vassalo sequestrado pelo bispo. Antes, porém, de a cena terminar, os camponeses pedem aos dois cavaleiros que os ajudem a se vingar dos homens de armas do bispo, com quem acabaram de brigar. O pedido é recusado e os cavaleiros saem. Os dois camponeses, aborrecidos, reclamam que os cavaleiros não fazem mesmo nada por eles, a menos que se lhes molhe a mão, e vão no encalço dos dois homens que querem surrar, como desejam um dia surrar os príncipes que os esfolam. São esses mesmos camponeses que, no último ato, atearão fogo às cidades e forçarão Götz a figurar como líder de sua revolta.

Muitas outras cenas apresentarão o mesmo padrão: uma situação se arma e segue seu curso até que, de um detalhe, se desdobrará a próxima ação. No caso da cena referida acima, os dois cavaleiros de Berlichingen 
vão dar a Götz, que há cinco dias está à espreita num albergue no bosque, a notícia de que Weislingen está num castelo próximo. Götz, então, efetuará o ataque que resultará na captura desse cavaleiro. Tendo-o como refém, Götz negociará a libertação de seu vassalo, que está em mãos do bispo de Bamberg.

Há também cenas montadas a partir de digressões ou de diálogos reflexivos que iluminam algum aspecto da realidade da trama, em geral expressando a opinião de Goethe sobre o tema ou a época.

É o que acontece com a cena imediatamente posterior à dos cavaleiros que deixam a taverna e vão à procura de Götz no albergue, onde ele espera a melhor oportunidade de capturar Weislingen. No início da cena, o menino Georg, que, ao longo da peça se tornará o mais fiel ajudante de armas de Götz, aparece vestido numa armadura de adulto e pede para ser integrado aos homens de Berlichingen. Em seguida, chega um monge, significativamente chamado Martinho, que se queixa da vida monacal e das restrições impostas aos sacerdotes: o desejo de prosperar é contido pelo voto de pobreza, o desejo de constituir família e se perpetuar nos filhos é refreado pelo voto de castidade; a liberdade, que impulsiona aos grandes feitos, é minada pelo voto da obediência e até o vinho, que exalta o cavaleiro, amolece o sacerdote. A conversa tem o claro propósito de elogiar a vida livre dos cavaleiros e, por antonomásia, criticar todos os que se opõem a ela, não só a Igreja Católica, mas também as cortes, que jogam o jogo da obediência em relação ao imperador para melhor servir aos próprios interesses. Enquanto a conversa se desenrola, Götz manda Georg colar o ouvido ao solo para antecipar a chegada dos cavaleiros e com isso dar prosseguimento a seu plano de capturar Weislingen. O passado também é apresentado: quando o frade descobre que está diante de Götz, faz questão de recordar o combate em que o cavaleiro perdeu a mão, elogiando sua coragem e determinação. Ainda durante o relato do frade, chegam os dois cavaleiros e, a partir das informações que eles trazem, Götz arma sua estratégia. Portanto, a digressão sobre a Igreja Católica não apenas veicula as ideias de Goethe a respeito dela, mas insere o tema num painel social mais amplo, no qual se contrapõem a espontaneidade, a naturalidade da conduta humana e a artificialidade da vida nas cortes ou nos mosteiros, além de antecipar o futuro: o frade dá a Georg um santinho de São Jorge, o guerreiro em quem o menino vai, a partir de então, se mirar.

A história de Georg é um dos marcadores temporais mais evidentes da peça: no primeiro ato o menino ganha uma pequena estampa 
de São Jorge, no segundo ato está entre os homens de confiança de Götz e é por ele enviado a Bamberg em missão secreta, da qual retorna com a notícia da traição de Weislingen; a partir do terceiro ato Georg acompanha todos os combates de Götz, até ser morto pelas tropas imperiais que reprimiam a revolta dos camponeses aos quais Götz é praticamente obrigado a se aliar. Saber da morte de Georg foi o golpe final para Götz, que o estimava como a um filho e sucessor. Clamando por liberdade e vaticinando tempos de perfídia, Götz morre diante de sua mulher, Elizabeth, de sua irmã, Marie, e de Lerse, um de seus mais fiéis cavaleiros:

\begin{abstract}
GÖTZ - Deus seja louvado! Georg era o melhor rapaz do mundo e o mais valente! Senhor, libertai, agora, a minha alma. Pobre mulher: deixo-te em um mundo corrompido. Lerse, não a abandones. Trancai os corações com mais cuidado do que as portas: os tempos de perfídia se avizinham; o caminho está aberto para eles. Reinarão pela astúcia, os miseráveis! O coração nobre se enredará em suas tramas. - Marie, que Deus te devolva teu esposo! Que ele não tombe das alturas às quais se elevou!... Selbitz morreu, e o bom imperador, e meu Georg!... Um copo d'água... Ar celeste... Liberdade! Liberdade!...
\end{abstract}

Morre.

ELISABETH - Só lá no alto, lá no alto, estarás em casa; o mundo é uma prisão.

MARIE - Homem nobre! Homem generoso! Infeliz do século que te rejeitou!

LERSE - Infeliz da posteridade que te desconhece!

(ato $v$, cena final; tradução minha)

A morte de Georg, mais do que a morte de Götz, significa o fim de uma era: com ele morre qualquer possibilidade de futuro para a liberdade dos cavaleiros. Quem quiser sobreviver, terá de se curvar ao jugo das cortes e dos príncipes. $\mathrm{E}$ os tempos se entrelaçam na cena final da peça: o passado medieval lança um grito em direção ao século XVIII alemão, que ignora sua história e sua tradição. Se, aos olhos do jovem Goethe, os dois séculos que o separam do Cavaleiro de Berlichingen foram, para a Alemanha, tempos de esquecimento de si mesma e de seus valores fundamentais, o medievo só lhe poderia parecer uma idade de ouro.

A contraposição entre a liberdade individual do cavaleiro e a artificialidade, a astúcia e o servilismo que imperam nas cortes aparece não só nas muitas cenas em que Götz é louvado por seu sentido de justiça, sua 
generosidade, sua disposição para defender os oprimidos, mas também nas cenas que se passam na corte do bispo de Bamberg. Lá, a maquinação impera e quem conduz as tramoias é Adelaide, mulher-demônio (personagem do agrado dos Stürmer) que seduz Weislingen; este, por causa dela, trai Götz, seu amigo de infância, e rompe o noivado com Marie. Adelaide seduz também o ajudante de ordens de Weislingen, que acaba por envenenar o patrão. Weislingen intriga Götz junto ao imperador e se revela extremamente cruel ao ser nomeado interventor oficial na guerra dos camponeses, torturando e matando os prisioneiros e condenando Götz à morte.

No entanto, a grosseria dos camponeses e a violência a que se entregam, uma vez iniciada a revolta, não nos faz supor que a razão esteja do lado deles. Eles também traem a confiança de Götz, que, forçado a se tornar líder das revoltas, «aceita» a tarefa por quatro semanas, desde que cessem as violências, as pilhagens e os incêndios. Nesse meio tempo, ele tentaria apresentar ao imperador a causa dos camponeses contra os nobres que os escorchavam. Contudo, quando fizeram o trato com Götz, os camponeses já estavam divididos a respeito da cessação dos ataques e sabiam que não seria possível cumprir o prometido. Era tudo o que os inimigos de Götz desejavam: uma acusação concreta contra ele para o fazer cair em desgraça e obter a sua condenação à morte.

Apesar de propor para sua peça de estreia uma estrutura bem mais flexível do que aquela que caracterizava o teatro trágico francês, Goethe constrói uma unidade de interesse em torno da trajetória de seu protagonista. É como se ele o observasse por um prisma que refrata em várias direções a luz que dele emana. Há, efetivamente, novidades na estruturação do tempo e do espaço em Götz. Walter Stewart (1978) aponta, por exemplo, o trabalho com a simultaneidade: duas cenas apresentadas em sequência na peça poderiam ter sua ordem invertida, visto que ambas se passam ao mesmo tempo. No entanto, apesar do estilhaçamento do espaço e do alongamento do tempo, Götz se singulariza em relação a outras peças do mesmo período pela organização interna e pela necessidade que liga todas as ações. A linguagem é bem articulada e, apesar de a História ser apenas um pano de fundo, a percepção de seu fluxo fica bem estabelecida, o que não ocorre, por exemplo, com a peça de Klinger, Sturm und Drang, que acabou por dar título ao movimento.

A estreia do espetáculo se deu em Berlim, em 1773, pela companhia de Koch. Em 1774 o espetáculo é montado em Hamburgo, em adaptação de Schröder. $\mathrm{O}$ fato de alguns atores terem de desempenhar dois 
ou mais papéis tornou a decodificação do espetáculo muito confusa. O público ficou fascinado com a fidelidade dos figurinos de época (a partir de então, passou a criar-se figurinos adequados, em vez de apenas acrescentar adereços a um vago traje de corte francês que servia para qualquer tipo de peça). Também os numerosíssimos ambientes apresentados na peça acabaram por forçar a ampliação dos palcos, que deveriam ser capazes de acolher todos os figurantes e a maquinaria requerida, e engendrou um novo padrão de mudança de cenário: a cortina se fechava entre um ato e outro e as mudanças dentro dos atos se faziam à vista do público, utilizando a alternância entre a cena profunda e a cena rasa.

Aos poucos, as plateias, habituadas às apresentações do drama burguês, que oferecia um mínimo de realismo, passaram a admirar o grande espetáculo, e Götz foi muito montado e muito imitado no século seguinte, gerando uma espécie de drama de cavalaria que poderia ser definido como um drama doméstico em ambiente exótico. É preciso dizer também que, à força de atuarem em personagens guerreiras e violentas, os atores acabaram por tornar seu trabalho mais grosseiro e sem nuance (Brufford, 1975: 229).

Em 1804, quando Napoleão estava a ponto de esmagar os alemães, Goethe decide retomar Götz para montar no Teatro de Weimar, que dirigia. Com a ajuda de Schiller, tenta fazer uma adaptação, que foi um malogro. Apesar de ter reduzido o número de mudanças de cena a vinte e quatro apenas, o espetáculo durou seis horas, e as personagens perderam em sutileza e definição, fazendo que o interesse da peça se diluísse devido à sua extensão. Outras estratégias foram tentadas: numa sessão (29 de setembro de 1804), foram apresentados os atos 1 e 2, e duas semanas depois os atos 3, 4, e 5 (a 13 de outubro de 1804). A crítica foi bastante desfavorável, e Goethe retrucou:

Esses bobos cismaram que o mais adequado seria copiar a forma do antigo Götz, com sua falta de regras, como se eu tivesse conscientemente escoIhido escrever daquele jeito. Naquela época, eu não conhecia nada melhor e escrevi o que me deu na telha. (apud Carlson, 1978: 221)

Goethe era muito cético em relação à influência real que a peça exerceu em sua época, comentando, não sem ironia, que não conseguiu despertar o interesse de seus contemporâneos pela visada histórica e que as peças de sucesso escritas e representadas com êxito se voltaram novamente para a vida privada, como Agnes Bernauerin e Othon de Wittelsbach (Goethe, 1988b: 398). 
A vida privada foi o tema de sua obra seguinte, Os Sofrimentos do Jovem Werther, romance epistolar escrito em um mês, que obteve sucesso estrondoso e no qual transpareciam os anseios dos jovens Stürmer e o tédio e a falta de perspectiva da mocidade alemã daquela época, como assinala Goethe em suas memórias (Goethe, 1971: 443-55). Vemos, nas palavras do próprio Werther, «uma ladainha de antíteses» (Goethe, 1988c: 105): a natureza se opõe ao formalismo, na arte e na convivência social; o sentimento e a imaginação se opõem ao frio raciocínio e às conveniências; o gênio romântico se opõe ao bom senso burguês, e assim sucessivamente. A visada sentimental é claramente tributária dos poetas ingleses de sua época, de Diderot, de Rousseau, enfim, de todos aqueles que, em maior ou menor grau, pretendiam explorar os recônditos ou o reverso da razão e a forma epistolar se prestava à perfeição aos derramamentos do coração. Anos depois, já na maturidade, a avaliação de Goethe a respeito desse período era que o sucesso lhe tomou tempo demais (Goethe, 1971: 524) e que o livro, que releu uma única vez, dez anos depois da publicação, foi «alimentado com o sangue de seu coração», tendo brotado de uma iluminação, um ímpeto criativo próprio da juventude, embora se tenha mantido não porque falava à juventude de sua época, mas porque há tantas incompreensões e tantos não-ditos entre os seres humanos de qualquer tempo (Goethe, 1988b:453-4, 551).

Para concluir este sobrevoo dos valores do Sturm und Drang, gostaria de lembrar brevemente que todos esses embates entre a poética de viés francês e a necessidade imperiosa de criar uma obra que correspondesse ao gênio alemão aparecem no romance de juventude $A$ Missão Teatral de Wilhelm Meister, que depois serviu de base para Os Anos de Aprendizado de Wilhelm Meister.

O romance $A$ Missão Teatral foi começado em 1775 e o trabalho prosseguiu até 1786, quando Goethe partiu para a Itália, deixando-o de lado. $\mathrm{A}$ «missão teatral» de Wilhelm é polir o trabalho de uma trupe de atores ambulantes que encontra por acaso num albergue durante uma viagem pela Alemanha. Filho de burgueses, Wilhelm sempre se havia mostrado avesso ao comércio. Apesar dessa indisposição, a família decide, depois que o jovem se recupera de uma longa enfermidade, mandá-lo cobrar algumas dívidas do negócio e ver o mundo. Wilhelm estava se saindo bem até que, apiedado da indigência artística e financeira da trupe, resolve ajudá-los, oferecendo-lhes novos figurinos, certo de que conseguiria reaver o dinheiro na próxima cidade em que se apresentassem. A paixão pelo teatro é mostrada quase como um vício: o jogador não 
consegue parar e acaba juntando seu destino ao dos miseráveis atores. O panorama artístico-teatral da época é descrito sem complacência: trupes mambembes vão de cidade em cidade, preocupadas com o pão de cada dia, dobrando-se às exigências do público; passando fome, sendo recebidas pelos nobres com desprezo, mas servindo para abrilhantar suas festas e satisfazer a sua luxúria. As discussões entre os partidários de um teatro à francesa e os de Shakespeare são talvez o eixo do romance, e a grande viagem tem um norte: a cidade de $\mathrm{H}^{* * *}$, provavelmente Hamburgo (evocação da experiência de Lessing com o Teatro Nacional?), onde Wilhelm acredita poder agregar os atores à companhia de seu amigo Serlo, que, num primeiro momento, os descarta, porque os acha muito ruins. Depois, para poder reter Wilhelm, Serlo promete aproveitar os atores em papéis secundários, nos quais não comprometeriam o nível geral da companhia. Muitas vezes, como diretor do teatro de Weimar, Goethe se viu na situação de Serlo, tendo de empregar famílias inteiras de atores apenas porque um dos membros da família seria uma aquisição positiva para sua equipe.

O interesse por Shakespeare pode ser considerado o fio condutor do romance, na medida em que a missão de Wilhelm é levar o grupo a representar Hamlet. Por fim, Wilhelm consente em deixar a posição de mecenas e representar ele mesmo o Príncipe da Dinamarca. O jogo entre o real e o ficcional se instala de forma instigante: o teatro de Shakespeare, é, em meio à matéria ficcional do romance, o que há de mais real, e conseguir torná-lo real, na ficção, encenando-o, assemelha-se à empresa à qual Goethe se propõe na Alemanha, despertando-a do torpor em que vivia e repetindo, em escala maior, o impacto que a leitura do bardo inglês teve sobre ele, curando-o subitamente da cegueira (cultural) em que vivia.

Cavaleiros, amantes e mambembes: várias épocas, várias ópticas, variadas relações entre o real e o ficcional: uma peça baseada num livro de memórias do medievo; um romance epistolar inspirado num fait divers (o suicídio do jovem Jerusalém que se havia apaixonado pela esposa de um amigo) e um romance de formação ou de evolução em que uma trupe corta a Alemanha em busca da segurança de um teatro permanente. $\mathrm{E}$, sobretudo, a certeza de que, num país em que a literatura começou pela crítica e pela teoria, como bem observou Mme. de Staël (1968: 183), a criação estética recebeu dos jovens integrantes do Sturm und Drang um poderoso estímulo para seu florescimento. 


\section{REFERÊNCIAS BIBLIOGRÁFICAS}

ARIST Ót E LES (1994), Poética, trad. Eudoro de Souza, 4. ${ }^{\mathrm{a}}$ ed. [s.l.], Imprensa Nacional-Casa da Moeda. BRUFFORD, W. H (1975), Theatre, Drama and Audience in Goethe's Germany, Westport/Connecticut, Greenwood Press.

CARLSON, Marvin (1978), Goethe at the Weimar Theatre, Ithaca, Cornell University Press.

ELIAS, Norbert (1990), O Processo Civilizador: Uma história dos costumes, trad. Ruy Jungmann, Rio de Janeiro, Jorge Zahar.

Goethe (1971), Poesia e Verdade, trad. Leonel Vallandro, Porto Alegre, Editora Globo.

-- (1987), «Sobre a arquitetura alemã», in LOBo, Luíza (trad., seleção e notas), Teorias Poéticas do Romantismo, Porto Alegre, Mercado Aberto, pp. 21-24.

-- (1988a), Théâtre complet, Paris, Encyclopédie de la Pléiade.

-- (1988b), Conversations de Goethe avec Eckermann, trad. Jean Chuzeville, Paris, Gallimard, 1988.

-- (1988c), Os Sofrimentos do Jovem Werther, trad. Erlon José Paschoal, São Paulo, Editora Clube do Livro.

GRAPPIN, Pierre, «Notice» (1988), in GoEThe, Théâtre complet, Paris, Encyclopédie de la Pléiade, pp. 1533-45.

LENZ (2006), «Notas sobre o teatro», in Lenz e Goethe, trad. Fátima Saadi, Rio de Janeiro, 7letras, pp. 27-61.

Stä̈L, Mme. de (1968), De l'Allemagne, vol. I, Paris, Flammarion.

STEWART, Walter K. (1978), Time Structure in Drama: Goethe's Sturm und Drang plays, Amesterdão, Rodopi.

\section{FÁTIMA SAADI}

Fátima Saadi é dramaturgista do Teatro do Pequeno Gesto (Rio/Rio de Janeiro), editora da revista Folhetim e da coleção Folhetim/Ensaios e tradutora. Formada em Teoria do Teatro, é doutorada em Comunicação e Cultura pela Universidade Federal do Rio de Janeiro. 